\title{
Comparison of Five Expression Vectors for the Ha Gene in Constructing a DNA Vaccine for H6N2 Influenza Virus in Chickens
}

\author{
Songhua Shan, Trevor Ellis, John Edwards, Stan Fenwick, Ian Robertson \\ School of Veterinary and Life Sciences, Murdoch University, Perth, Australia \\ Email: Songhua.shan@CSIRO.AU
}

Received 5 March 2016; accepted 17 April 2016; published 20 April 2016

Copyright $@ 2016$ by authors and Scientific Research Publishing Inc.

This work is licensed under the Creative Commons Attribution International License (CC BY). http://creativecommons.org/licenses/by/4.0/

(c) $\underset{\mathrm{EY}}{\mathrm{B}}$ Open Access

\begin{abstract}
A number of eukaryotic expression vectors have been developed for use as DNA vaccines. They showed varying abilities to initiate immune responses; however, there is little data to indicate which of these vectors will be the most useful and practical for DNA vaccines in different species. This report examines the use of five expression vectors with different promoters and Kozak sequence to express the same hemagglutinin (HA) protein of an H6N2 avian influenza virus for DNA vaccination in chickens. Although intramuscular vaccination with seven DNA constructs elicited no or limited measurable $\mathrm{H} 6 \mathrm{HA}$ antibody responses in Hy-Line chickens, variable reduction in virus shedding for either oropharyngeal or cloacal swabs post-virus challenge were observed. This indicated that all DNA constructs generated some levels of protective immunity against homologous virus challenge. Interestingly, lower dose (50 or $100 \mu \mathrm{g}$ ) of plasmid DNAs consistently induced better immune response than higher dose $(300$ or $500 \mu \mathrm{g})$. In the transfection experiments there appeared to be a hierarchy in the in vitro expression efficiency in the order of pCAG-optiHAk/ pCAG-HAk > pCI-HAk > VR-HA > pCI-HA > pCI-neo-HA > pVAX-HA. Since the level of in vitro expression correlates with the level of immune response in vivo, in vitro expression levels of the DNA constructs can be used as an indicator for pre-selection of plasmid vaccines prior to in vivo assessment. Moreover, our results suggested that the Kozak sequence could be used as an effective tool for DNA vaccine design.
\end{abstract}

\section{Keywords}

DNA Vaccine, Multiple Expressing Vectors, H6N2 Avian Influenza a Virus, Chickens

\section{Introduction}

DNA-based immunization has pioneered a new era of vaccine research. DNA vaccine is a purified self-repli-

How to cite this paper: Shan, S.H., Ellis, T., Edwards, J., Fenwick, S. and Robertson, I. (2016) Comparison of Five Expression Vectors for the Ha Gene in Constructing a DNA Vaccine for H6N2 Influenza Virus in Chickens. Advances in Microbiology, 6, 310-319. http://dx.doi.org/10.4236/aim.2016.64030 
cating bacterial plasmid vector encoding foreign antigens. It generally consists of two components: 1) a mammalian expression cassette (promoter/enhancer, antigen-encoding DNA and polyadenylation sequences) and 2) the bacterial plasmid backbone (necessary for plasmid amplification and selection) [1] [2]. DNA vaccines expressing the haemagglutinin (HA) gene of avian influenza viruses (AIVs) have provided solid immune protection against influenza virus infections in chickens [3]-[8]. However, immunogenicity of DNA vaccines in chickens has been variable depending on DNA expression vector used [8], gene inserted (antigenicity of encoded insert) [9] [10], animal species [11] or mouse strain [12], injected DNA dose [10] [13] [14], volume [15], application methods and delivery route [9] [16].

Among these factors affecting DNA vaccine efficacy, selection of an appropriate vector used for expression of the antigen can have a huge impact on immunogenicity [2]. A promoter/enhancer, responsible for transcriptional initiation, is critical to successfully drive the expression of heterologous genes of interest [8] [13] [14]. Other elements, such as intron, polyadenylation signals and the plasmid backbone sequence, can also affect the level of expression of the antigen [1] [10] [17] [18]. Moreover, the insertion of a Kozak sequence and the use of a codon optimised gene may have marked effects on gene expression efficiency [5] [17].

To date, a number of expression vectors have been developed and used in DNA vaccine research. The VR1012 vector, which contains CMV/IE promoter, bovine growth hormone (BGH) polyadenylation site and $\mathrm{Kan}^{\mathrm{r}}$ gene in a modified pUC backbone, encoding NP and M gene from PR8 virus [19] [20], or encoding HA from A/turkey/Wisconsin/68 (H5N9) [8], induced protective immunity against lethal challenge to some extent. The pCI and pCI-neo vector, which contain the CMV/IE enhancer/promoter region, a $\beta$-globin/IgG chimeric intron and an SV40 late polyadenylation signal, have been used to generate vaccine plasmid pCI HA or pCI-neo HA which elicited measurable antibody titres in chickens against A/Goose/Guangdong/1/96 (H5N1) or A/turkey/Wisconsin/68 (H5N9) respectively [3] [8]. The pVAX1 vector, which contains CMV/IE enhancer/promoter and BGH polyadenylation signal, but lacks an intron in its backbone, was employed to clone HA, neuraminidase (NA) and matrix (M1) consensus sequences from circulating H5 AIV to generate recombinant constructs, which induced highly cross-reactive cellular immune responses against H5 influenza antigens in mice [21]. The vector pCAGGS, containing the chicken $\beta$-actin promoter, the CMV enhancer and a rabbit $\beta$-globin poly (A) sequence has been shown to be effective in DNA vaccines for H5 AIV [5] and influenza [22]. Although many expression vectors showed their effectiveness for DNA vaccination, the data on which of these vectors will be the most useful and practical for use with DNA vaccines is seldom available. In this study, we compared five expression vectors expressing the same HA gene of an H6N2 influenza virus, resulting in seven DNA constructs, in an attempt to assess the effect of eukaryotic expression vectors on immunity in commercial chickens using an avian influenza model as a proof-of-concept study.

\section{Materials and Methods}

\subsection{Preparation of DNA Constructs}

The full-length HA gene of A/coot/WA/2727/79 (H6N2) was amplified by reverse transcriptase-polymerase chain reaction (RT-PCR) and cloned into the VR10102 vector (VR) (provided by Dr Cassandra James, Murdoch University, Australia) to generate the VR-HA construct as previously described [23]. Forward and reverse primers for amplifying HA gene were respectively aaCTGCAGCAAAAGCAGGGGAAAATG and cgcGGATCCTTTCTAATTATATACATATYYTGC (Restriction endonuclease sequence is in italic). The complete open reading frame (ORF) of A/coot/WA/2727/79 (H6N2) virus HA gene was 1701 nucleotides long and encoded a protein of 576 amino acids (GenBank accession No. CY028243). Protective nucleotide bases in lower case were added before recognition sites for restriction endonuclease). The HA gene was subcloned into the pCI or pCI-neo vectors (kindly provided by Dr David Suarez, Southeast Poultry Research Laboratory, USA) at the EcoRI and XmaI sites to generate pCI-HA and pCI-neo-HA constructs and was similarly subcloned into the pVAX1 vector (provided by Professor Graham Wilcox, Murdoch University, Australia) at the EcoRI and HindIII sites to generate the pVAX-HA construct. The HA gene or a chicken codon-optimized HA gene, incorporating a Kozak enhancer sequence, was cloned into a pCAGGS vector to produce the pCAG-HAk and pCAG-optiHAk constructs as previously described [24]. The HA gene was subcloned from the pCAG-HAk vector into the pCI vector at the EcoRI and SmaI sites to generate a pCI-HAk construct. The plasmid DNAs were prepared using the alkaline lysis method as described previously [25]. 


\subsection{Transient Expression of Recombinant Plasmids in Eukaryotic Cells}

Chicken embryo fibroblast (CEF) cells, human embryonic kidney cells (293T), African green monkey kidney cells (Cos-7) and hamster kidney cells (BSR) were prepared using standard procedures. The Cos-7 cells were transfected transiently using FuGENE ${ }^{\mathbb{B}}$ HD Transfection Reagent (Roche Diagnostics Australia Pty. Ltd., NSW, Australia) or Lipofectamine ${ }^{\mathrm{TM}} 2000$ (Invitrogen Corp, CA, USA) following the manufacturer's protocol. The expression products of DNA constructs were identified after 36 - $48 \mathrm{~h}$ by either Western blotting or immunofluorescent test (IFT) with an H6 specific polyclonal antibody as described [23].

\subsection{Experimental Design of the Vaccination and Challenge Study}

The Hy-Line layer pullets (supplied by Altona Hatchery Pty. Ltd., Australia), serologically negative for avian influenza A virus as determined by blocking ELISA [26], were raised in a free-range pen and fed commercial poultry feed and water ad lib. DNA vaccine formulations with lipofectin adjuvant were conducted as described [8].

The vaccinated birds were bled by venepuncture every two weeks (every week for experiment 3 ) to measure the H6-specific antibodies using haemagglutination inhibition (HI), ELISA or immunoblotting assay (Shan 2010a). Each chicken received a total dose of $1 \mathrm{~mL}$ of challenge virus $\left(\operatorname{EID}_{50} 10^{6.25}-\operatorname{EID}_{50} 10^{7.25} / 0.1 \mathrm{~mL}\right)$ given via the intranasal $(0.25 \mathrm{ml})$, conjunctival $(0.25 \mathrm{ml})$ and oral $(0.5 \mathrm{ml})$ routes. Following virus challenge, swabs were collected daily for virus isolation as described previously [27].

The immunization regime in experiment 1 was shown in Table 1. Four groups of three 6 -week-old chickens each were injected intramuscularly twice at 3-week interval with 100 or $500 \mu \mathrm{g}$ VR-HA or blank vector (VR) plasmid DNA dissolved in $0.2 \mathrm{~mL} 0.9 \% \mathrm{NaCl}$, with or without lipofectin as adjuvant. A third intramuscular injection of their respective dose of plasmid DNA together with lipofectin was given 6 weeks later after booster. Selected groups were subjected to virus challenge at 7 weeks following the last vaccination. The control group was injected intramuscularly with $1 \mathrm{~mL}$ of inactivated $\mathrm{H} 6 \mathrm{~N} 2$ virus vaccine (IVV) [28].

The immunization regime in experiment 2, using plasmids pCI-HA, pCI-neo-HA, pVAX-HA or IVV, was similar to the procedure described previously [29]. Each group of five 3-week-old birds received two separate injections in the breast muscle of $0.2 \mathrm{~mL}$ plasmid DNA diluted in PBS, with or without lipofectin adjuvant, three times at 4-week intervals. Virus challenge was done at $6-7$ weeks after the third vaccination.

In experiment 3, each group of five 3-week-old birds and a naive control group with six birds were vaccinated twice at 3-week intervals with $100 \mu \mathrm{g}$ pCAG-HAk, pCAG-optiHAk or pCI-HAk vaccine constructs. Virus challenge was done at three weeks after the second vaccination.

Birds following challenge were euthanased and packed in sealed biosafety containers, including composting and leftover feed, for incineration.

\subsection{Data Analysis}

All statistical analysis of HI antibody titres was conducted as geometric mean titres (GMT). Statistical analyses of experimental data and controls were conducted by using the paired-sample T-test, and one way analysis of variance (ANOVA) (Mann-Whitney Test was used as homogeneity of variance testing showed statistical significance) with SPSS statistical software version 15 as well as Chi-square (Fisher's exact test was used when the sample number was less than 5) using Statistix. Statistical significance was defined at the level of $\mathrm{P}<0.05$.

Table 1. Antibody conversion in chickens immunized with VR-HA construct in experiment 1.

\begin{tabular}{ccccccc}
\hline & Age (wk) & IVV & $100 \mu \mathrm{g} \mathrm{VR}^{*}$ & $100 \mu \mathrm{g} \mathrm{VR}-\mathrm{HA}^{*}$ & $500 \mu \mathrm{g}$ VR-HA & $500 \mu \mathrm{g} \mathrm{VR}-\mathrm{HA}^{*}$ \\
\hline $1^{\text {st }}$ vaccination & 6 & $3 / 3(3.8 \pm 1.3)^{* *}$ & $0 / 3$ & $0 / 3$ & $0 / 3$ & $0 / 3$ \\
$2^{\text {nd }}$ vaccination & 9 & $3 / 3(6.0 \pm 1.2)^{\mathrm{A}}$ & $0 / 3$ & $0 / 3$ & $0 / 3$ & $0 / 3$ \\
$3^{\text {rd }}$ vaccination & 15 & $0 / 3)^{\mathrm{A}}$ & $1 / 3(0.7 \pm 1.2)^{\mathrm{A}}$ & $0 / 3$ & $1 / 3^{* * * \mathrm{~A}}$ \\
Post virus challenge & 22 & $3 / 3(9.6 \pm 1.7)^{\mathrm{B}}$ & $3 / 3(7.7 \pm 4.0)^{\mathrm{B}}$ & $3 / 3(6.7 \pm 0.6)^{\mathrm{B}}$ & $3 / 3(8.7 \pm 4.7)^{\mathrm{B}}$ \\
\hline
\end{tabular}

"Plasmid DNA plus adjuvant; ${ }^{* *}$ Number of sero-conversions/total number of vaccinated chickens (HI titre shown as GMT $\left(\log _{2}\right) \pm$ standard deviation (SD)); Within the column the different uppercase superscript letter indicates statistical differences $(\mathrm{P}<0.05) ;{ }^{* * *}$ Immunoblotting antibody. 


\section{Results}

\subsection{In vitro Expression of Different HA-Expressing Constructs}

The resultant DNA constructs by DNA recombinant technology were identified by restriction endonuclease digestions and further confirmed for the fidelity of the HA gene and insertional direction using sequencing. As shown in Figure 1, the pCAG-HAk and pCAG-optiHA constructs gave the strongest bands. Next was the pCI-HAk construct. These three constructs were at least 4-fold stronger in band intensity than either the pCI-HA or VR-HA constructs and the band intensity for VR-HA was clearly stronger than that for pCI-HA. Similarly, in another transfection experiment, the pCI-HA gave the strongest band, followed by the pCI-neo-HA, and the weakeast band was the pVAX-HA (picture not shown).

The hierarchy of different DNA constructs in the in vitro expression efficiency obtained by IFT test in CEF, Cos-7, 293T and BSR cells was similar to those by Western blotting, namely pCAG-optiHAk/pCAG-HAk > pCI-HAk > VR-HA > pCI-HA > pCI-neo-HA > pVAX-HA. As shown in Figure 2, Cos-7 cells transfected with the pCI-HA displayed brightest fluorescence in the cytoplasm and cell membrane. The next strongest staining intensity was with the pCI-neo-HA. The pVAX-HA transfected cells showed only limited fluorescence.

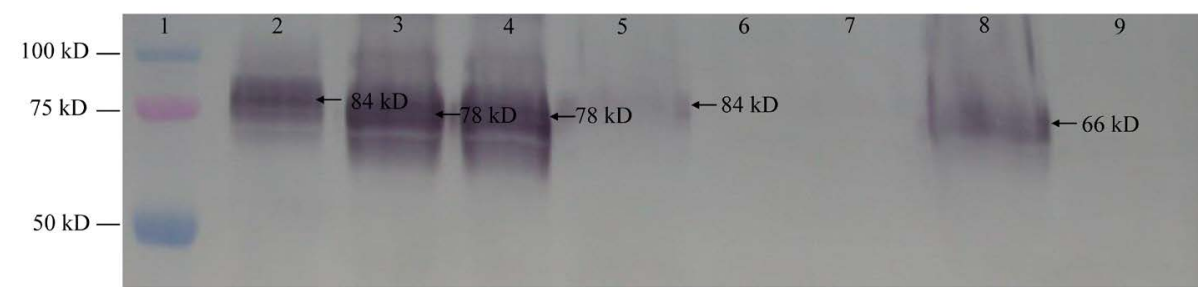

Figure 1. HA protein expression in DNA construct transfected Cos 7 cells by Western blotting. Lane 1: marker (Bio-Rad); lane 2: pCI-HAk (84 kD); lane 3: pCAG-HAk (78 kD); lane 4: pCAG-optiHAk; lane 5: pCI-HA (84 kD); lane 6: pCI; lane 7: pCAGGS; lane 8: VR-HA (66 kD); lane 9: VR1012.

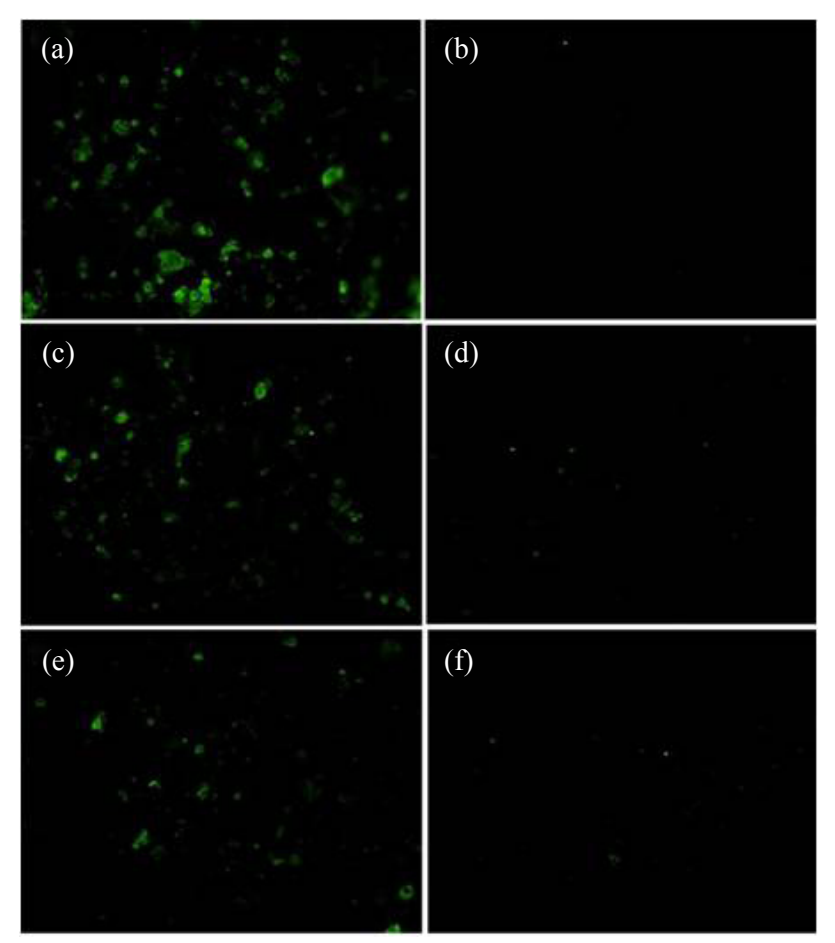

Figure 2. Fluorescence occurring in three H6 HA-expressing DNA vaccine constructs expressed in Cos-7 cells (x10). (a) pCI-HA; (b) pCI; (c) pCI-neo-HA; (d) pCI-neo; (e) pVAX-HA; (f) pVAX1 vector. 


\subsection{Antibody Responses in Vaccinated Chickens}

In experiment 1 , chickens administered $100 \mu \mathrm{g}$ or $500 \mu \mathrm{g}$ VR-HA twice with or without lipofectin adjuvant did not induce measurable antibody. Following three vaccinations, only one chicken from the $100 \mu \mathrm{g}$ adjuvanted VR-HA group produced a low level of HI antibody $\left(2^{1}\right)$, which was confirmed by immunoblotting assay (Table 1). Another chicken from the $500 \mu \mathrm{g}$ adjuvanted group did not develop HI antibody, but its immunoblotting antibody titre was $1 / 20$. No antibody was detected in other immunized chickens. The HI titre in VR-HA vaccinated chickens on 10 days post challenge ranged from $2^{5}$ to $2^{14}$ in the VR-HA vaccinated groups.

In Experiment 2, no HI titre was detected in any pCI-HA, pCI-neo-HA and pVAX-HA vaccinated chickens 6 weeks after the first, second or third vaccination. However, at 7 days post virus challenge the chickens showed a range of HI titres (Table 2). There was a significant difference in the geometric mean titres (GMT) of HI antibody post challenge between the $100 \mu \mathrm{g}$ adjuvanted pCI-HA group and the naive control group, the non-adjuvanted and the adjuvanted pCI-HA groups. However, this was not observed in pCI-neo-HA and pVAX-HA groups.

In Experiment 3, no $\mathrm{HI}$ antibody production was measurable in Hy-line chickens vaccinated with the $100 \mu \mathrm{g}$ pCI-HAk, pCAG-HAk or pCAG-optiHAk plasmids. However, all three vaccine groups and the naive control group showed a significant increase in GMT of HI antibody after challenge (Table 3).

\subsection{Virus Shedding in Vaccinated Chickens Following Virus Challenge}

No clinical signs were observed in both vaccinated and control groups following an H6N2 low pathogenicity AIV challenge.

As illustrated in Table 4, virus shedding in the blank vector vaccinated chickens occurred intermittently over the observation period after challenge. In comparison with the blank vector group, the $100 \mu \mathrm{g}$ VR-HA group showed a highly significant decrease in virus shedding in oropharyngeal and cloacal swabs, but this did not occur in the $500 \mu \mathrm{g}$ VR-HA group. Moreover, the $100 \mu \mathrm{g}$ VR-HA group was significantly different in virus shedding for oropharyngeal and cloacal swabs from the $500 \mu \mathrm{g}$ VR-HA group.

Table 2. Antibody response prior to challenge (PRC) and post challenge (POC) for naive controls, inactivated vaccine (IVV) and different DNA vaccine groups (pCI-HA, pCI-HA-neo and pVAX-HA) at the doses indicated (in $\mu \mathrm{g}$ ) in experiment 2.

\begin{tabular}{|c|c|c|c|c|c|c|c|c|c|c|c|c|c|}
\hline & \multirow{2}{*}{$\begin{array}{l}\text { Naive } \\
\text { control }\end{array}$} & \multirow{2}{*}{ IVV } & \multicolumn{4}{|c|}{ pCI-HA } & \multicolumn{4}{|c|}{ pCI-HA-neo } & \multicolumn{3}{|c|}{ pVAX-HA } \\
\hline & & & 50 & 100 & 300 & $100 *$ & 50 & 100 & 300 & $100^{*}$ & 50 & 100 & 300 \\
\hline PRC & $0^{* * \mathrm{Aa}}$ & $\begin{array}{l}8.6 \pm \\
1.1^{\mathrm{Ab}}\end{array}$ & $0^{\mathrm{Aa}}$ & $0^{\mathrm{Aa}}$ & $0^{\mathrm{Aa}}$ & $0^{\mathrm{Aa}}$ & $0^{\mathrm{Aa}}$ & $0^{\mathrm{Aa}}$ & $0^{\mathrm{Aa}}$ & $0^{\mathrm{Aa}}$ & $0^{\mathrm{Aa}}$ & $0^{\mathrm{Aa}}$ & $0^{\mathrm{Aa}}$ \\
\hline POC & $\begin{array}{l}4.5 \pm \\
0.6^{\mathrm{Ba}}\end{array}$ & $\begin{array}{l}9.8^{ \pm} \\
0.5^{\mathrm{Ab}}\end{array}$ & $\begin{array}{l}3.2 \pm \\
1.3^{\mathrm{Bac}}\end{array}$ & $\begin{array}{l}5.2 \pm \\
1.6^{\mathrm{Bac}}\end{array}$ & $\begin{array}{l}5.2 \pm \\
1.3^{\mathrm{Bac}}\end{array}$ & $\begin{array}{l}8.3^{ \pm} \\
1.3^{\mathrm{Bdf}}\end{array}$ & $\begin{array}{l}4.4 \pm \\
2.6^{\mathrm{Bac}}\end{array}$ & $\begin{array}{l}5.4 \pm \\
1.1^{\mathrm{Bac}}\end{array}$ & $\begin{array}{c}6.2 \pm \\
2.2^{\text {Bacf }}\end{array}$ & $\begin{array}{l}4.8 \pm \\
1.0^{\mathrm{Bae}}\end{array}$ & $\begin{array}{l}4.9 \pm \\
2.1^{\mathrm{Bac}}\end{array}$ & $\begin{array}{l}3.6 \pm \\
1.1^{\mathrm{Bac}}\end{array}$ & $\begin{array}{c}6.4 \pm \\
2.1^{\text {Bacf }}\end{array}$ \\
\hline
\end{tabular}

*Adjuvant group; ${ }^{* *} \mathrm{HI}$ titre of each group shown as GMT $\left(\log _{2}\right) \pm$ standard deviation (SD); Within the column the different uppercase superscript letter indicates statistical differences $(\mathrm{P}<0.05)$ using Paired-sample $\mathrm{T}$ test. For the row groups with different lowercase superscript letter are significantly different $(\mathrm{P}<0.05)$ using ANOVA or Mann-Whitney test.

Table 3. Antibody conversion and virus shedding in oropharyngeal (OS) and cloacal swabs (CS) in chickens immunized with different DNA constructs (pCAG-HAk, pCAG-optiHA and pCI-HAk) following virus challenge in Experiment 3.

\begin{tabular}{|c|c|c|c|c|}
\hline & Naïve control & pCAG-HAk & pCAG-optiHA & pCI-HAk \\
\hline \multicolumn{5}{|l|}{ Antibody response } \\
\hline Prior to challenge & 0 & 0 & 0 & 0 \\
\hline Post challenge & $6.0 \pm 2.0^{*}$ & $5.6 \pm 1.7$ & $5.0 \pm 3.4$ & $8.2 \pm 2.2$ \\
\hline \multicolumn{5}{|l|}{ Virus shedding } \\
\hline Oropharyngeal swabs & $17 / 24(70.8)^{* * a}$ & $9 / 20(45)^{\mathrm{a}}$ & $12 / 20(60)^{\mathrm{a}}$ & $12 / 20(60)^{\mathrm{a}}$ \\
\hline Cloacal swabs & $3 / 24(12.5)^{\mathrm{a}}$ & $0 / 20(0)^{\mathrm{a}}$ & $0 / 20(0)^{\mathrm{a}}$ & $1 / 20(5)^{\mathrm{a}}$ \\
\hline
\end{tabular}

${ }^{*}$ HI titre of each group shown as GMT $\left(\log _{2}\right) \pm$ standard deviation (SD); ${ }^{* *}$ No. of swabs positive for virus isolation/total number of swabs tested. Percentages are shown in parentheses. For the row groups with different lowercase superscript letter are significantly different $(\mathrm{P}<0.05)$ using Chi-square or Fisher exact tests. 
Table 4. Virus recovery in oropharyngeal (OS) and cloacal swabs (CS) from the vaccinated and control groups post-challenge in experiment 1.

\begin{tabular}{ccccc}
\hline & IVV & $100 \mu \mathrm{g}$ VR-HA & $500 \mu \mathrm{g}$ VR-HA & $100 \mu \mathrm{g}$ VR \\
\hline OS & $2 / 18(11.1)^{\mathrm{a}}$ & $3 / 18(16.7)^{\mathrm{a}}$ & $10 / 18(55.6)^{\mathrm{b}}$ & $14 / 18(77.8)^{\mathrm{b}}$ \\
CS & $0 / 18(0)^{\mathrm{a}}$ & $0 / 18(0)^{\mathrm{a}}$ & $5 / 18(27.8)^{\mathrm{b}}$ & $10 / 18(55.6)^{\mathrm{b}}$
\end{tabular}

HA positive numbers/total sample numbers. Percentages are shown in parenthesis; For the row groups with different lowercase superscript letter are significantly different $(\mathrm{P}<0.05)$ using Chi-square or Fisher exact tests.

As summarized in Table 5, in non-adjuvanted groups, there was no significant difference in virus shedding in oropharyngeal swabs between the naïve control group and any of the HA-expressing DNA vaccine groups except for the $300 \mu \mathrm{g}$ pCI-HA group (Chi-square, $\mathrm{P}=0.043$ ). However, there were significant differences in the level of virus shedding in cloacal swabs between the naïve control group and the groups vaccinated with 50,100 and $300 \mu \mathrm{g}$ pCI-HA; 50 and $100 \mu \mathrm{g}$ pCI-neo-HA; or $50 \mu \mathrm{g}$ pVAX-HA. For adjuvanted groups, there were no significant differences in virus shedding in oropharyngeal swabs but significant differences in cloacal swabs between the naïve control group and either the adjuvanted $100 \mu \mathrm{g}$ pCI-HA or $100 \mu \mathrm{g}$ pCI-neo-HA groups.

In addition, there were significant reduction in virus shedding via the oropharynx in chickens between the 50 $\mu \mathrm{g}$ and $300 \mu \mathrm{g}, 100 \mu \mathrm{g}$ and $300 \mu \mathrm{g}$ of the pCI-HA vaccine. Significant differences also occurred in cloacal shedding between $100 \mu \mathrm{g}$ and $300 \mu \mathrm{g}$ doses of the HA-pCI-neo vaccine and between $50 \mu \mathrm{g}$ and $300 \mu \mathrm{g}$ doses of pVAX-HA.

As shown in Table 3, there appeared to be a reduction in virus recovery from oropharyngeal and cloacal swabs in all three vaccinated groups compared with the naive control group. In terms of percentage of virus recovery from oropharyngeal and coacal swabs, the pCAG-HAk group was lower than the pCAG-optiHAk or the pCI-HAk groups although there were no significant differences.

\section{Discussions}

Efficient expression of heterologous genes in an appropriate eukaryotic vector is a prerequisite for the development of DNA vaccines. The impact of expression vectors on immune responses has been reported by comparing two plasmid configurations [9] [13] [14] [30]-[32], or three plasmid vectors [2]. Little has been reported on the comparison of multiple expression vectors [8]. In this study, five expression vectors containing different combinations of the widely used CMV promoter and the chicken $\beta$-actin promoter as well as various enhancer and polyadenylation sequences were investigated to provide information on the selection of an appropriate vector for the development of a DNA vaccine in chickens. Although the three experiments were not conduced at the same time with the same immunization regimen, similar findings were demonstrated with seven HA-expressing DNA constructs (VR-HA, pCI-HA, pCIneo-HA, pVAX-HA, pCI-HAk, pCAG-HAk and pCAG-optiHAk) in three experiments. All seven HA-expressing DNA constructs gave no or poor antibody responses to the H6 virus HA, even using more sensitive antibody detection methods (ELISA and immunoblotting assay). Nevertheless, all DNA vaccinated groups showed rapidly increasing antibody responses to virus challenge. Although statistical aberrations due to small group sizes cannot be ruled out, there were statistically significant increases in antibody titre between pre- and post-challenge in most DNA constructs and the inactivated vaccine group, but not observed in blank vector or naive control groups. This suggested that DNA vaccination at least provided some evidence of playing a priming role in the antibody response following virus challenge.

With regard to virus excretion post-virus challenge, as compared with the empty VR vector controls, there was an apparent reduction in virus shedding in oropharyngeal and cloacal swabs in VR-HA groups, however, greater reduction in virus shedding was observed in the inactivated vaccine group. This indicated that the VR-HA vaccine was inefficient at reducing virus shedding following virus challenge. Similarly, when compared to the naive control chickens, there appeared to be a reduction in virus shedding post-challenge in cloacal swabs (experiment 2 and 3 ) and oropharyngeal swabs (experiment 3 ) in vaccinated chickens post challenge. This indicated that all these DNA vaccines generated some levels of protective immunity against homologous virus challenge.

In experiment 1 , although there was no significant difference in virus titre shed via oropharynx between lower dose and higher dose groups of the VR-HA construct, the frequency of virus shedding in cloacal and oropharyngeal swabs was significantly lower in the lower dose $(100 \mu \mathrm{g})$ groups than in the higher dose $(500 \mu \mathrm{g})$ 
Table 5. Virus shedding post challenge in oropharyngeal (OS) and cloacal swabs (CS) in unvaccinated chickens and chickens vaccinated with inactivated vaccine (IVV) or different DNA vaccine groups (pCI-HA, pCI-neo-HA and pVAX-HA) at the doses $(\mu \mathrm{g})$ indicated in experiment 2 .

\begin{tabular}{|c|c|c|c|c|c|c|c|c|c|c|c|c|c|}
\hline & \multirow{2}{*}{$\begin{array}{l}\text { Naive } \\
\text { control }\end{array}$} & \multirow{2}{*}{ IVV } & \multicolumn{4}{|c|}{ pCI-HA } & \multicolumn{4}{|c|}{ pCI-neo-HA } & \multicolumn{3}{|c|}{ pVAX-HA } \\
\hline & & & 50 & 100 & 300 & $100^{* *}$ & 50 & 100 & 300 & $100^{* *}$ & 50 & 100 & 300 \\
\hline $\begin{array}{l}\mathrm{O} \\
\mathrm{S}\end{array}$ & $\begin{array}{c}13 / 28 \\
(46.4)^{* a}\end{array}$ & $0 / 35^{\mathrm{bc}}$ & $\begin{array}{c}15 / 35 \\
(42.9)^{\text {ade }}\end{array}$ & $\begin{array}{c}14 / 35 \\
(40.0)^{\text {ade }}\end{array}$ & $\begin{array}{c}25 / 35 \\
(71.4)^{\text {bcf }}\end{array}$ & $\begin{array}{c}9 / 28 \\
(32.1)^{\text {ad }}\end{array}$ & $\begin{array}{c}19 / 35 \\
(54.3)^{\mathrm{ac}}\end{array}$ & $\begin{array}{c}17 / 35 \\
(48.6)^{\text {ad }}\end{array}$ & $\begin{array}{c}12 / 35 \\
(34.3)^{\text {ad }}\end{array}$ & $\begin{array}{c}9 / 28 \\
(32.1)^{\text {ad }}\end{array}$ & $\begin{array}{c}16 / 28 \\
(57.1)^{\mathrm{ac}}\end{array}$ & $\begin{array}{c}19 / 35 \\
(54.3)^{\text {ac }}\end{array}$ & $\begin{array}{c}15 / 35 \\
(42.9)^{\mathrm{ad}}\end{array}$ \\
\hline $\begin{array}{l}\mathrm{C} \\
\mathrm{S}\end{array}$ & $\begin{array}{c}9 / 28 \\
(32.1)^{\mathrm{a}}\end{array}$ & $\begin{array}{c}4 / 35 \\
(11.4)^{\mathrm{ac}}\end{array}$ & $\begin{array}{c}3 / 35 \\
(8.57)^{\mathrm{bc}}\end{array}$ & $0 / 35^{\mathrm{bc}}$ & $\begin{array}{c}3 / 35 \\
(8.57)^{\mathrm{bc}}\end{array}$ & $0 / 28^{b c}$ & $\begin{array}{c}3 / 35 \\
(8.57)^{\text {bce }}\end{array}$ & $0 / 35^{\mathrm{bc}}$ & $\begin{array}{c}7 / 35 \\
(20.0)^{\text {aef }}\end{array}$ & $\begin{array}{c}1 / 28 \\
(3.57)^{\mathrm{bcf}}\end{array}$ & $0 / 28^{\mathrm{bc}}$ & $\begin{array}{c}4 / 35 \\
(11.4)^{\mathrm{ac}}\end{array}$ & $\begin{array}{c}6 / 35 \\
(17.1)^{\mathrm{a}}\end{array}$ \\
\hline
\end{tabular}

${ }^{*}$ No. of bird swabs positive for virus isolation/total number of swabs tested from birds in the group (percentage); ${ }^{* *}$ Adjuvant group. For the row groups, statistical analysis is performed only in each of three HA-expressing construct groups, naïve control and inactivated vaccine group. Groups with different lowercase superscript letter in the row are significantly different $(\mathrm{P}<0.05)$ using Chi-square or Fisher's exact test.

groups. Similar results were obtained using the pCI-HA, pCI-neo-HA and pVAX-HA constructs. The lower dose groups $(50$ or $100 \mu \mathrm{g})$ appeared to be more effective at reducing virus shedding in cloacal swabs than the higher dose group $(300 \mu \mathrm{g})$. This suggested that lower doses of HA-expressing DNA vaccine appeared to induce better protective responses than higher doses. In an early HIV experiment, higher amounts of plasmid encoding cytotoxic T lymphocyte (CTL) epitopes of HIV gp160 gave lower CTL responses after single gene gun immunization [9]. Another study showed similar results [13]. The reason why the lower dose induced better immune response is not yet fully understood. Presumably, large amounts of plasmid might generate too vigorous cellular immune responses which perhaps kill off the transfected cells too early to maintain immune stimulation, thereby resulting in attenuated vaccine responses [9]. Moreover, the possibility that high dose DNA is introduced into extracellular spaces by the intramuscular route, potentially leading to a more rapid clearance of DNA, cannot be ruled out [11].

DNA vaccines have been demonstrated to elicit antibody responses since their first description in 1990 [33], but their capacity to induce antibody responses has been shown to be quite variable in chickens [3] [6]. In a previous study, chickens vaccinated with an H5 AIV DNA vaccine by gene gun did not produce detectable prechallenge antibodies, but produced high antibody titre and provided complete protection after homologous virus challenge [6]. Our results showed similarities with that study. All DNA constructs did not induce measurable antibody before challenge in Hy-Line chickens, but showed different degree of reduction in virus shedding via oropharynx and cloaca post virus challenge. Since DNA vaccines induce antibody and cell-mediated immune response, one can speculate that evidence of protection after DNA vaccination in the absence of humoral immunity is considered an indicator of cellular immunity, although cellular immune indicators [6] were not able to be measured in this study.

Some DNA vaccination studies indicate that there was a direct correlation between the level of protein expression in vitro and immunogenicity in mice [34], pigs [30] and chickens [5] [8]. In the present study, although the various HA-expressing DNA construct vaccines did not induce significant antibody responses, there was some enhanced HA antibody responses and some reduction in virus shedding after virus challenge with these vaccines. This varied between the DNA vaccine constructs in a way that tended to correlate with their level of in vitro expression in Cos-7 mammalian cells. Overall, the transfection experiments showed a hierarchy in the in vitro expression efficiency in the order of pCAG-optiHAk/pCAG-HAk $>$ pCI-HAk $>$ VR-HA $>$ pCI-HA $>$ pCI-neo-HA $>$ pVAX-HA, but with the constructs containing Kozak sequence clearly stronger than the others. In the virus challenge experiments the $100 \mu \mathrm{g}$ adjuvanted VR-HA vaccine reduced virus expression compared with the blank plasmid control (Experiment 1) to a greater extent than $100 \mu \mathrm{g}$ adjuvanted pCI-HA vaccine compared with the naive control (Experiment 2). Similarly, the reduction in virus shedding in oropharyngeal and cloacal swabs in Experiment 2 trended to be less in birds vaccinated with $100 \mu \mathrm{g}$ pVAX-HA, than with $100 \mu \mathrm{g}$ pCI-neo-HA, than with $100 \mu \mathrm{g}$ pCI-HA constructs. This was consistent with the level of HA expression shown in Cos-7 cells in Figure 2. In Experiment 3, the three Kozak sequence containing constructs which showed similar levels of expression in Cos-7 cells by Western blotting showed similar apparent reduction in virus shedding in oropharyngeal and cloacal swabs but with the trend of pCAG-optiHAk/pCAG-HAk > pCI-HAk compared with the naive controls. The in vivo comparison between pCI-HA and pCI-HAk vaccine constructs was not able to be done in this study.

In other studies, the level of protein expression following transfection into mammalian or avian cells by other DNA pCAG-optiHAk constructs showed a direct relationship with the magnitude of immune responses in 
chickens receiving these DNA vaccines [24]. Also, with the trend evident in this study that the level of in vitro expression correlates with the level of immune response in vivo, it is proposed that in vitro expression levels of the plasmid vaccines be used as an indicator for pre-selection of plasmid DNA vaccines prior to costly in vivo evaluation of a DNA vaccine.

As illustrated in Figure 1, the difference in band intensity of expression between the pCI-HAk and the pCI-HA (Kozak effect) was much greater than that between the pCAG-HAk and pCI-HAk (vector effect). This indicated that the Kozak sequence appeared to play a more important role in initiating protein expression among these three DNA constructs than the vector effect. It highlighted that the Kozak sequence could be used as an effective tool to increase the expression of target genes for DNA vaccine design in chickens. In vitro expression experiments with the pCAG-HAk vector also demonstrated that both the Kozak sequence and the pCAGGS vector were accountable for the increased level of expression, suggesting that both had a synergistic effect on the expression of DNA constructs. Therefore, optimization of an expression vector and insertion of a Kozak sequence could be used to potentially increase the efficacy of DNA vaccines in chickens.

\section{Acknowledgements}

We would like to acknowledge and thank Professor Hualan Chen for allowing us to prepare the pCAG-HAk construct at the Avian Influenza Reference Laboratory at Harbin Veterinary Research Institute, China.

\section{References}

[1] Gurunathan, S., Klinman, D.M. and Seder, R.A. (2000) DNA Vaccines: Immunology, Application, and Optimization. The Annual Review of Immunology, 18, 927-974. http://dx.doi.org/10.1146/annurev.immunol.18.1.927

[2] Miller, M., Rekas, G., Dayball, K., Wan, Y.H. and Bramson, J. (2004) The Efficacy of Electroporated Plasmid Vaccines Correlates with Long-Term Antigen Production in Vivo. Vaccine, 22, 2517-2523. http://dx.doi.org/10.1016/j.vaccine.2004.01.019

[3] Chen, H., Yu, K., Jiang, Y. and Tang, X. (2001) DNA Immunization Elicits High HI Antibody and Protects Chicken from AIV Challenge. International Congress Series, 1219, 917-921. http://dx.doi.org/10.1016/S0531-5131(01)00368-5

[4] Cherbonnel, M., Rousset, J. and Jestin, V. (2003) Strategies to Improve Protection against Low-Pathogenicity H7 Avian Influenza Virus Infection Using DNA Vaccines. Avian Diseases, 47, 1181-1186. http://dx.doi.org/10.1637/0005-2086-47.s3.1181

[5] Jiang, Y., Yu, K., Zhang, H., Zhang, P., Li, C., Tian, G., Li, Y., Wang, X., Ge, J., Bu, Z. and Chen, H. (2007) Enhanced Protective Efficacy of H5 Subtype Avian Influenza DNA Vaccine with Codon Optimized HA Gene in a pCAGGS Plasmid Vector. Antiviral Research, 75, 234-241. http://dx.doi.org/10.1016/j.antiviral.2007.03.009

[6] Kodihalli, S., Haynes, J.R., Robinson, H.L. and Webster, R.G. (1997) Cross-Protection among Lethal H5N2 Influenza Viruses Induced by DNA Vaccine to the Hemagglutinin. Journal of Virology, 71, 3391-3396.

[7] Kodihalli, S., Kobasa, D.L. and Webster, R.G. (2000) Strategies for Inducing Protection against Avian Influenza A Virus Subtypes with DNA Vaccines. Vaccine, 18, 2592-2599. http://dx.doi.org/10.1016/S0264-410X(99)00485-5

[8] Suarez, D.L. and Schultz-Cherry, S. (2000) The Effect of Eukaryotic Expression Vectors and Adjuvants on DNA Vaccines in Chickens Using an Avian Influenza Model. Avian Diseases, 44, 861-868. http://dx.doi.org/10.2307/1593058

[9] Barry, M.A. and Johnston, S.A. (1997) Biological Features of Genetic Immunization. Vaccine, 15, 788-791. http://dx.doi.org/10.1016/S0264-410X(96)00265-4

[10] Doria-Rose, N.A. and Haigwood, N.L. (2003) DNA Vaccine Strategies: Candidates for Immune Modulation and Immunization Regimens. Methods, 31, 207-216. http://dx.doi.org/10.1016/S1046-2023(03)00135-X

[11] Babiuk, L.A., Pontarollo, R., Babiuk, S., Loehr, B. and van Drunen Littel-van den Hurk, S. (2003) Induction of Immune Responses by DNA Vaccines in Large Animals. Vaccine, 21, 649-658. http://dx.doi.org/10.1016/S0264-410X(02)00574-1

[12] Chen, Z., Matsuo, K., Asanuma, H., Takahashi, H., Iwasaki, T., Suzuki, Y., Aizawa, C., Kurata, T. and Tamura, S. (1999) Enhanced Protection against a Lethal Influenza Virus Challenge by Immunization with Both Hemagglutininand Neuraminidase-Expressing DNAs. Vaccine, 17, 653-659. http://dx.doi.org/10.1016/S0264-410X(98)00247-3

[13] Davis, H.L., Whalen, R.G. and Demeneix, B.A. (1993) Direct Gene Transfer into Skeletal Muscle in Vivo: Factors Affecting Efficiency of Transfer and Stability of Expression. Human Gene Therapy, 4, 151-159. http://dx.doi.org/10.1089/hum.1993.4.2-151 
[14] Galvin, T.A., Muller, J. and Khan, A.S. (2000) Effect of Different Promoters on Immune Responses Elicited by HIV-1 Gag/Env Multigenic DNA Vaccine in Macaca Mulatta and Macaca Nemestrina. Vaccine, 18, 2566-2583. http://dx.doi.org/10.1016/S0264-410X(99)00569-1

[15] Dupuis, M., Denis-Mize, K., Woo, C., Goldbeck, C., Selby, M.J., Chen, M., Otten, G.R., Ulmer, J.B., Donnelly, J.J., Ott, G. and McDonald, D.M. (2000) Distribution of DNA Vaccines Determines Their Immunogenicity after Intramuscular Injection in Mice. The Journal of Immunology, 165, 2850-2858. http://dx.doi.org/10.4049/jimmunol.165.5.2850

[16] Wang, S., Zhang, C., Zhang, L., Li, J., Huang, Z. and Lu, S. (2008) The Relative Immunogenicity of DNA Vaccines Delivered by the Intramuscular Needle Injection, Electroporation and Gene Gun Methods. Vaccine, 26, 2100-2110. http://dx.doi.org/10.1016/j.vaccine.2008.02.033

[17] Garmory, H.S., Brown, K.A. and Titball, R.W. (2003) DNA Vaccines: Improving Expression of Antigens. Genetic Vaccines and Therapy, 1, 2. http://dx.doi.org/10.1186/1479-0556-1-2

[18] Sato, Y., Roman, M., Tighe, H., Lee, D., Corr, M., Nguyen, M.D., Silverman, G.J., Lotz, M., Carson, D.A. and Raz, E. (1996) Immunostimulatory DNA Sequences Necessary for Effective Intradermal Gene Immunization. Science, 273, 352-354. http://dx.doi.org/10.1126/science.273.5273.352

[19] Epstein, S.L., Tumpey, T.M., Misplon, J.A., Lo, C.Y., Cooper, L.A., Subbarao, K., Renshaw, M., Sambhara, S. and Katz, J.M. (2002) DNA Vaccine Expressing Conserved Influenza Virus Proteins Protective against H5N1 Challenge Infection in Mice. Emerging Infectious Diseases, 8, 796-801. http://dx.doi.org/10.3201/eid0805.010476

[20] Epstein, S.L., Kong, W.P., Misplon, J.A., Lo, C.Y., Tumpey, T.M., Xu, L. and Nabel, G.J. (2005) Protection against Multiple Influenza A Subtypes by Vaccination with Highly Conserved Nucleoprotein. Vaccine, 23, 5404-5410. http://dx.doi.org/10.1016/j.vaccine.2005.04.047

[21] Laddy, D.J., Yan, J., Corbitt, N., Kobasa, D., Kobinger, G.P. and Weiner, D.B. (2007) Immunogenicity of Novel Consensus-Based DNA Vaccines against Avian Influenza. Vaccine, 25, 2984-2989. http://dx.doi.org/10.1016/j.vaccine.2007.01.063

[22] Chen, Z., Sahashi, Y., Matsuo, K., Asanuma, H., Takahashi, H., Iwasaki, T., Suzuki, Y., Aizawa, C., Kurata, T. and Tamura, S. (1998) Comparison of the Ability of Viral Protein-Expressing Plasmid DNAs to Protect against Influenza. Vaccine, 16, 1544-1549. http://dx.doi.org/10.1016/S0264-410X(98)00043-7

[23] Shan, S.H. (2010) Development and Evaluation of DNA Vaccines in Chickens against a Wild Bird H6N2 Avian Influenza Virus from Western Australia. Ph.D. Dissertation, Murdoch University, Perth.

[24] Shan, S., Jiang, Y., Bu, Z., Ellis, T., Zeng, X., Edwards, J., Tian, G., Li, Y., Ge, J., Chen, H. and Fenwick, S. (2011) Strategies for Improving the Efficacy of a H6 Subtype Avian Influenza DNA Vaccine in Chickens. Journal of Virological Methods, 173, 220-226. http://dx.doi.org/10.1016/j.jviromet.2011.02.008

[25] Sambrook, J. and Russell, D.W. (2001) Molecular Cloning: A laboratory Manual. 3rd Edition, Cold Spring Harbor Laboratory Press, New York, 1.31-31.42 and 31.59-31.61.

[26] Pant, G.R. and Selleck, P.W. (2007) Surveillance for Avian Influenza in Nepal 2004-2005. Avian Diseases, 51, 352354. http://dx.doi.org/10.1637/7649-051806R.1

[27] Shan, S., Ellis, T.M., Fenwick, S., Edwards, J., O’Dea, M. and Parkinson, J. (2010b) Biological and Genetic Characterization of a Low-Pathogenicity Avian Influenza H6N2 Virus Originating from a Healthy Eurasian Coot. Archives of Virology, 155, 403-409. http://dx.doi.org/10.1007/s00705-010-0588-1

[28] James, C.M., Foong, Y.Y., Mansfield, J.P., Fenwick, S.G. and Ellis, T.M. (2007) Use of Tetanus Toxoid as a Differentiating Infected from Vaccinated Animals (DIVA) Strategy for Sero-Surveillance of Avian Influenza Virus Vaccination in Poultry. Vaccine, 25, 5892-5901. http://dx.doi.org/10.1016/j.vaccine.2007.05.023

[29] Lee, C.W., Senne, D.A. and Suarez, D.L. (2003) Development of Hemagglutinin Subtypespecific Reference Antisera by DNA Vaccination of Chickens. Avian Diseases, 47, 1051-1056. http://dx.doi.org/10.1637/0005-2086-47.s3.1051

[30] Melkebeek, V., Sonck, E., Verdonck, F., Goddeeris, B.M. and Cox, E. (2007) Optimized FaeG Expression and a Thermolabile Enterotoxin DNA Adjuvant Enhance Priming of an Intestinal Immune Response by an FaeG DNA Vaccine in Pigs. Clinical and Vaccine Immunology, 14, 28-35. http://dx.doi.org/10.1128/CVI.00268-06

[31] Uchijima, M., Yoshida, A., Nagata, T. and Koide, Y. (1998) Optimization of Codon Usage of Plasmid DNA Vaccine is Required for the Effective MHC Class I-Restricted T Cell Responses against an Intracellular Bacterium. The Journal of Immunology, 161, 5594-5599.

[32] van Drunen Littel-van den Hurk, S., Braun, R.P., Karvonen, B.C., King, T., Yoo, D. and Babiuk, L.A. (1999) Immune Responses and Protection Induced by DNA Vaccines Encoding Bovine Parainfluenza Virus Type 3 Glycoproteins. Virology, 260, 35-46. http://dx.doi.org/10.1006/viro.1999.9793

[33] Wolff, J.A., Malone, R.W., Williams, P., Chong, W., Acsadi, G., Jani, A. and Felgner, P.L. (1990) Direct Gene Transfer into Mouse Muscle in Vivo. Science, 247, 1465-1468. http://dx.doi.org/10.1126/science.1690918 
[34] Steinberg, T., Ohlschlager, P., Sehr, P., Osen, W. and Gissmann, L. (2005) Modification of HPV 16 E7 Genes: Correlation between the Level of Protein Expression and CTL Response after Immunization of C57BL/6 Mice. Vaccine, 23, 1149-1157. http://dx.doi.org/10.1016/j.vaccine.2004.08.027 